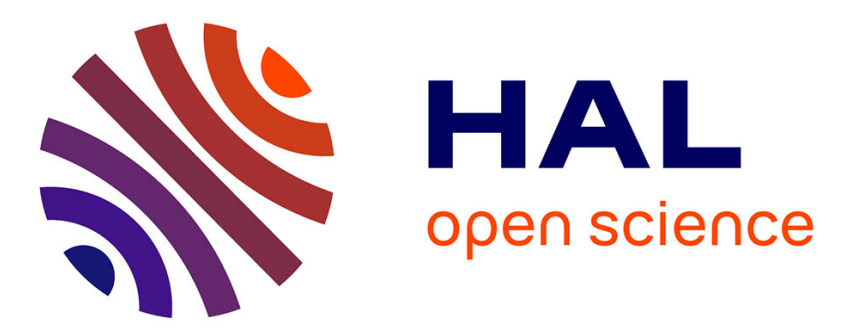

\title{
Experimental pressure solution compaction of synthetic halite/calcite aggregates.
}

Sergey Zubtsov, François Renard, Jean-Pierre Gratier, Robert Guiguet, Dag K. Dysthe, Vladimir Traskine

\section{> To cite this version:}

Sergey Zubtsov, François Renard, Jean-Pierre Gratier, Robert Guiguet, Dag K. Dysthe, et al.. Experimental pressure solution compaction of synthetic halite/calcite aggregates.. Tectonophysics, 2004, 385, pp.45-57. 10.1016/j.tecto.2004.04.016 . hal-00105682

\section{HAL Id: hal-00105682 \\ https://hal.science/hal-00105682}

Submitted on 12 Oct 2006

HAL is a multi-disciplinary open access archive for the deposit and dissemination of scientific research documents, whether they are published or not. The documents may come from teaching and research institutions in France or abroad, or from public or private research centers.
L'archive ouverte pluridisciplinaire HAL, est destinée au dépôt et à la diffusion de documents scientifiques de niveau recherche, publiés ou non, émanant des établissements d'enseignement et de recherche français ou étrangers, des laboratoires publics ou privés. 


\section{Experimental pressure solution compaction of synthetic halite/calcite aggregates}

Sergey Zubtsov ${ }^{1,2}$, François Renard ${ }^{*}{ }^{1,3}$, Jean-Pierre Gratier ${ }^{1}$, Robert Guiguet ${ }^{1}$, Dag K. Dysthe ${ }^{3}$, Vladimir Traskine ${ }^{2}$

${ }^{1}$ LGIT-CNRS-Observatoire, Université Joseph Fourier, BP 53, 38041 Grenoble, France

${ }^{2}$ Chemistry Department, Moscow State University, Russia

${ }^{3}$ PGP, Physics of Geological Processes, University of Oslo, Norway

Corresponding author: François Renard, LGIT, Université Joseph Fourier, BP 53X, 38041 Grenoble, France.

Email: francois.renard@lgit.obs.ujf-grenoble.fr.

Tel: +33 (0) 476828 088, Fax: +33 (0) 476828101. 


\begin{abstract}
Experimental observations are reported of weakening of sediment-like aggregates by addition of hard particles. Sieved mixtures of calcite and halite grains are experimentally compacted in drained pressure cells in the presence of a saturated aqueous solution. The individual halite grains deform easily by pressure solution creep whereas calcite grains act as hard objects and resist compaction. The fastest rate of compaction of the mixed aggregate is not obtained for a $100 \%$ halite aggregate but for a content of halite grains between $45 \%$ and $75 \%$. We propose that this unusual compaction behavior reflects the competition between two mechanisms at the grain scale: intergranular pressure solution at grain contacts and grain boundary healing between halite grains that prevent further compaction.
\end{abstract}

Key words: compaction, diagenesis, halite, polymineralic aggregate, pressure solution creep 


\section{Introduction}

During burial, sediments may undergo a transformation from a loose aggregate into a solid porous rock with a finite strength. This is perhaps the most striking example of what is called strain hardening, the fact that the strength of a solid increases as this solid is deformed. With time, the sediment tends to compact into a hard rock by purely mechanical effects such as grain sliding and by dissolution-precipitation processes responsible for grain indentation and cementation. All these mechanisms reduce the pore volume.

Pressure solution is a mechanism whereby the concentration of normal stress at grain contacts causes local dissolution of the material, transport of the solutes out of the contact site and precipitation of the material on the less stressed faces of the grains (Weyl 1959; Rutter 1976). The rate of rock deformation by pressure solution is controlled by the slowest of the three above mentioned elementary stages. Estimated pressure solution deformation rates may vary by many orders of magnitude (den Brok 1998) because the fundamental processes are not yet clearly understood.

Deformation of polymineralic aggregates by pressure solution has not been investigated at any great length. One theoretical model of pressure solution creep of polymineralic rocks (Wheeler 1992) discusses the physico-chemical interactions of minerals in polymineralic aggregates during deformation by pressure solution. First, if different minerals share the same chemical components (e.g., most rock forming minerals contain silica), growth or dissolution of one phase will affect that of the other through the shared components. Second, the different components may affect each other's diffusion rates. 
There is another factor that is important for deformation behavior of polymineralic aggregates during pressure solution. If two grains on both sides of a grain contact have the same mineralogy and similar crystallographic orientations, this contact can heal and further dissolution will not be possible (Hickman and Evans 1991). Alternatively, for the edge contact of cleaved prismatic halite single crystals and the (100) face of halite single crystals, Schutjens and Spiers (1998) did not observe any healing. Hickman and Evans (1991) assumed, based on experimental studies and theoretical considerations, that the healing process is favored by several parameters: low normal stress, low density of surface defects, and large curvature radius of the grains.

Hickman and Evans (1995) have performed several experiments where a halite lens was pressed against a fused silica flat coated with $0.8 \mu \mathrm{m}$ thick film of Na-montmorillonite in brine. This clay film produced an approximately fivefold increase in convergence rates over those observed in a halite/silica experiment conducted without clay at the same load and temperature. It was proposed that the reason of this rate increase is the ability of montmorillonite to maintain a high volume percentage of adsorbed (structured) water or interparticle bulk water between grains even under load. Because of this effect clays enhance the rate of solute diffusion in the experiment. It was also shown that that adding a small quantity of clay particles to a wet halite aggregate enhanced the rate of compaction by up to $50 \%$ (Renard et al. 2001). The increased compaction rate was argued to be due to enhanced diffusion or inhibition of grain boundary healing. This enhancement of pressure solution by other minerals has also been reported for the quartz-mica system (Rutter and Wanten 2000). However, to our knowledge, no systematic studies varying the proportions of minerals have been performed until now. 
As for experimental results presented below, it may be proposed that if two neighboring grains have a different mineralogy, this prevents healing and the bulk rate of aggregate deformation should be enhanced. To test this assumption we have carried out a series of compaction experiments with aggregates containing halite and calcite grains in different proportions.

\section{Experimental methods}

\subsection{Oedometric press}

Powders of polymineralic composition (calcite and halite) were experimentally deformed using a specially designed drained oedometric press (Fig. 1). Six of such presses could be run simultaneously on a bench in a thermostated Plexiglas box. The compaction of the samples was measured by monitoring a micro-scale glued on the piston with the 10-power objective of a microscope. As the movement of the scale recorded the displacement due to compaction, the vertical deformation was directly measured with a resolution of the displacement of $5 \mu \mathrm{m}$. A steel spring loaded the piston. The maximum value of the load was about $6.5 \mathrm{~kg}$, which corresponds to a vertical stress of 2.3 MPa. This value was used in all our experiments. During the experiment, the load varied by less than $10 \%$ because of spring uncoil.

\subsection{Preparation of the mixed aggregates}

Each sample is a mixture of halite and calcite grains. Halite crystals (pure $\mathrm{NaCl}$ from Rectapur) were ground dry using a mill, fractioned by various sieves, and then rinced with a saturated solution of water. The same method was applied for calcite. A sample of clean Carrara marble was used as initial material. Fractions $80-100 \mu \mathrm{m}$ of halite and calcite were mixed in required mass ratios. The powders were mixed with a spoon for five minutes and again for two minutes just before every experiment to obtain the best possible homogeneity. 
In order to correctly calculate the number fraction of grains from the weight fractions, 300 grains from a 50\%wt fraction mixture were counted using a microscope. Several drops of water were then added. After dissolution of all of the halite, 162 calcite grains remained. Thus this mixed aggregate contained $54 \%$ of calcite grains. Knowing that the density of calcite is higher than that of halite, this result seems to be incorrect. However, it can be explained easily if one supposes that the average diameter of halite grains in the fraction 80$100 \mu \mathrm{m}$ is slightly greater than that of calcite ones in the same fraction. Systematic measurements of the grain size were performed after the experiments and confirmed such a difference in the initial halite and calcite grain size distributions. Using the obtained value of calcite grain content, the weight percentages were converted into grain percentages for all mixtures used in our experiments (see Table 1).

\subsection{Compaction creep experiments}

The mixture of powders was soaked with an aqueous solution saturated with respect to halite and calcite. Then it was placed under vacuum for two minutes to remove bubbles of air. The evaporation of water during this de-aeration step is assumed to be negligible. The column was prepared as follows: 2 millimeters of wet powder were placed in the bottom of the tube, and then this powder was compacted applying a load of $0.7 \mathrm{MPa}$. These operations were repeated several times to obtain the desired aggregate height. The initial height of the column, $\mathrm{x}_{0}$, was measured with a mechanical micrometer. In all the experiments, columns 9-14 $\mathrm{mm}$ in height and $6 \mathrm{~mm}$ in diameter were used. A drop of liquid paraffin was placed at the top of the column to prevent evaporation of the solution. The cell was assembled and heated to $33^{\circ} \mathrm{C}$ inside a temperature-controlled box for one day. To start the experiment, the bolt at the top of the cell was screwed-in to achieve the desired loading stress of 2.3 MPa (Fig. 1). The moment at which this operation was completed was taken to be the start time. The cells were then placed in the thermostated box. The duration of each experiment was about five days. 
Deformation up to $27 \%$ was observed. The significant inelastic deformation during the initial 3 minutes of the experiment, presumably due to grain sliding and plastic deformation, was not taken into account.

\section{Experimental results}

Fourty-nine experiments have been carried out covering a range of calcite and halite mixtures from 0 to $100 \mathrm{wt} \%$ in $5-10 \%$ intervals (see Table 1). The experiments on mixed aggregates of fractionated powders of halite and calcite were performed in a saturated solution of halite and calcite at $33^{\circ} \mathrm{C}$ under an initial calculated vertical stress of $2.3 \mathrm{MPa}$. They were run for five days.

\subsection{Effect of the mineral fraction on the compaction}

The result of the experiments is a set of compaction curves. The vertical shortening is expressed as a percentage of the initial height of the column of powder. If $x_{0}$ is the initial height of the sample, $\varepsilon(t)=\left(x_{0}-x(t)\right) / x_{0}$ corresponds to the vertical deformation at time $t$. Eight of these curves are presented in Fig. 2 where the effect of the proportion of halite grains on the overall compaction is clearly shown. Using all compaction curves, a curve was constructed representing the effect of the mineralogical composition on the amount of vertical shortening of the sample during the period from 100 to 7000 minutes of compaction (Fig. 3a). It shows that the maximum compaction occurred for a proportion of halite grains between $45 \%$ and $75 \%$ (compaction of around $21 \%$ ) whereas an aggregate of $100 \%$ halite grains was compacted only up to $17 \%$. As a consequence, the compaction is $24 \%$ higher for a proportion of halite grains between $45 \%$ and $75 \%$ than for a pure halite aggregate. The value of error bars in all our graphs is

$$
\delta=\sqrt{\frac{1}{N} \sum_{i=1}^{N}\left(\varepsilon_{i}-\varepsilon_{\text {average }}\right)^{2}}
$$


where $N$ is the number of experiments for a fixed halite-calcite proportion, $\varepsilon_{i}$ is the deformation value obtained for the experiment $i$, and $\varepsilon_{\text {average }}$ corresponds to the average deformation in the $N$ experiments. The errors in the inital proportions of halite and calcite are negligible.

\subsection{Compaction homogeneity throughout the height of the column}

For purely elastic aggregates in a cylinder the vertical force across a plane changes with height (Janssen 1895). However, Renard et al. (2001) showed by imaging that $\varepsilon(t)$ is homogeneous throughout the column. To further check this, five experiments with pure halite and seven experiments with $70 \mathrm{wt} \%$ halite content powders were performed with different initial heights of the column (Fig. 4). The low spreading between the curves are assumed to be due to experimental errors and to the initial arrangement of the grains, which varies randomly between each experiment. The initial height of the sample has no effect on the degree of compaction, thus indicating that the variations of the friction on the side of the cells between each experiment are negligible. Therefore it may be concluded, that for $80-100 \mu \mathrm{m}$ powder with a column height less than about $30 \mathrm{~mm}$, the sample bears the same load over its entire height and compacts homogeneously.

\subsection{Verification of the dominant mechanism of compaction}

To be certain that plastic deformation and grain sliding were not the dominant deformation mechanisms during wet compaction, one dry experiment and one experiment with liquid paraffin were performed under normal experimental conditions with a $100 \%$ halite aggregate. In both cases, the compaction was less than $0.5 \%$ (Fig. 5).

To see wether the mechanism of powder deformation was the same throughout the experiments three curves similar to the curves of Fig. 3a were plotted for deformation 
intervals [100-300], [300-3000] and [3000-7000] minutes (Fig. 6). The only difference with the curves of Fig. 3a is that here deformation is normalized to the maximum deformation (equal to 1) for each curve. Fig. 6 shows that the shape of the strain vs halite content curves is the same within the limits of experimental error on the interval $40 \%-100 \%$ of halite content. It means that the ratio between deformation rates for any two mixtures of different halite content higher than $40 \%$ remained constant throughout the experiment from about 100 minutes onwards. This observation can be considered as an indirect evidence that the deformation mechanism on these intervals remained unchanged during the experiments.

For the mixtures with halite content from $0 \%$ to about $40 \%$, the deformation mechanism seemed to be different (Fig. 6). The curves of normalized deformation and their error bars do not overlap for the three different time intervals [100-300], [300-3000], and [3000-7000] minutes. It shows that the normalized compaction rate for low halite content mixtures evolved differently with time from those with high halite content. We propose that, in this case, calcite grains formed a hard continuous network that was resistant to deformation by pressure solution. Only some halite inclusions were subjected to the deformation. But as the halite grains deformed, local rearrangement of calcite grains occured from time to time. In other words, there were small local collapses of the network of calcite grains. Fig. 6 shows that, as the experiment proceeded (from the squares, through diamonds and to circles on Fig. 6), there was a reduction in average deformation at the given elapsed time in the $0-40 \%$ halite content range. It would appear that, as the experiment proceeded, an increasing number of halite grains became deformed so that only the continuous network of calcite grains supported the load. Because of this effect, the stress on the halite grains diminished with time and consequently, the load and the rate of deformation went down.

\subsection{Effect of the initial composition on the compaction rate}


For each compaction curve (Fig. 2) the rate of compaction was calculated at 7000 minutes.

On the basis of these data, a curve showing the effect of the mineralogical composition on the rate of deformation was constructed (Fig. 3b). The shape of this curve is identical to that of all the curves that showed the effect of the mineralogical composition on the amount of finite deformation (Fig. 3a and 5) within the limits of experimental errors.

\subsection{Effect of initial defects on crystal surfaces}

The powders were prepared by grinding. As a result the concentration of defects on grain surfaces were probably enhanced. If these grains are placed in a saturated solution of halite, some recrystallisation can take place and the defects may progressively disappear. It may be possible that the initially present defects enhanced the rate of deformation of crystals by pressure solution. To verify this possibility, experiments were performed with powders that had spent between 1 and 4 days in a saturated solution (Fig. 4a). The compaction rate with these different initial powders was the same in all these experiments. This indicates that any initial defects content did not affect the compaction curve.

\subsection{Porosity estimations}

The porosities of initial dry aggregates with $70 \mathrm{wt} \%$ and $100 \mathrm{wt} \%$ of halite have been measured. For this purpose some quantities of the powder mixtures were placed in burettes, which were then knocked by a pencil for several minutes to obtain the least possible porosity of the powders. Masses and volumes of powders were measured and porosities were calculated from these data, using calcite and halite density values. Both for $70 \mathrm{wt} \%$ and 100 $\mathrm{wt} \%$ halite mixtures, the value of porosities $47 \pm 1 \%$ was obtained. This value is high as pointy grains with edges hooked into each other. The first effect of pressure solution is to dissolve such contacts. From these data, it may be concluded that the mineral composition of the aggregates has no significant influence on its starting porosity. As it will be shown later, even 
after the experiments, no significant grain crushing could be observed in the wet aggregates. Therefore, it was inferred that the previous conclusion could be extended to the case of precompacted wet aggregates that we used in these experiments.

\subsection{Microstructure observations}

After completing the experiment, each aggregate was removed from its cell. If the content of halite in the initial mixture was less than about $30 \%$, the sample after deformation was still a loose aggregate that fell apart when taking out of the container. If the content was greater, the sample had acquired cohesive strength and could be manipulated.

The aggregates with $0 \mathrm{wt} \%, 70 \mathrm{wt} \%$ and $100 \mathrm{wt} \%$ halite content were imaged by SEM after the experiments. For this purpose, an attempt was made to flush the samples with hexane under vacuum, but they were found to be impermeable except the first one. The solid aggregates ( $70 \mathrm{wt} \%$ and $100 \%$ of halite) were then broken in two parts in such a manner that the direction of vertical stress lies in the cutting plane.

Several SEM images of these three aggregates and of the initial halite and calcite powders are presented in Fig. 7. In particular, Fig. $7 \mathrm{~g}$ and $7 \mathrm{~h}$ show evidences of pressure solution, such as increase of the surface area of intergranular contact (Fig. 7g) and grain indentation (Fig. 7h).

In each image, the average size of halite and calcite grains before and after deformation was estimated. For each grain, the maximum dimension and its orthogonal maximum dimension were measured and the average of these two values was considered as the mean grain size. The $100 \%$ calcite aggregate showed the same average grain size of $103 \mu \mathrm{m}$ before and after deformation. Hence, it follows that there was no calcite grain crushing during the experiments. Unfortunately, it was not possible to measure the size of calcite grains after 
compaction of $70 \mathrm{wt} \%$ halite aggregate because the calcite grains were half-buried into the deformed halite grains making it impossible to measure their real dimensions without destroying the sample.

The initial halite powder showed an average grain size of $106 \mu \mathrm{m}$ and the average grain size of halite after compaction of $100 \%$ halite aggregate is $85 \mu \mathrm{m}$. The small cubes that one can see on the photos of the compacted aggregates correspond to halite crystals formed by evaporation of the saturated halite solution after the experiment. These cubes should not be taken into account. Therefore, the resulting diminution of average halite grain size was $20 \%$. This value accords well with the experimental value obtained for 100\% halite aggregates deformation after $7000 \mathrm{~min}$, that is $17 \%$. Thus, we can conclude that there was no halite grain crushing during the experiment.

\section{Discussion and modelling}

\subsection{Contact healing}

The driving force for pressure solution is related to stress variations along the grain surface (Paterson 1973). Pressure solution occurs in response to a non-zero effective stress, i.e., the normal stress component $\sigma_{n}$ across a grain contact is greater than the stress on the grain due to the normal (hydrostatic) stress in the adjacent pore. Thus, the chemical potential of a mineral can be seen to vary along the surface of a grain, driving the diffusive flux of solutes from the contact area to the free pore surface. This stress-driven process can lead to grain deformation and indentation. However, when the two grains on both sides of the contact have the same mineralogy and the same crystallographic orientation, the grain boundary can disappear as the two opposing surfaces match perfectly, this is the healing process. This has been observed when two lenses of halite are put in contact under stress (Hickman and Evans 
1991). Contact healing reduces the rate of grain indentation and therefore the overall rate of deformation of the whole aggregate. However, it should be noted that halite has a cubic crystal structure. This type of structure is beneficial for intergranular healing. For more complex crystals than halite, the probability of good crystallographic matching between two grains in contact is smaller.

The main result of the experiments (Fig. 3) is that the rate of compaction is not linearly proportional to the amount of halite grains in the aggregate. Adding hard particles in the aggregate decreases its resistance to compaction and weakens it. This effect is the consequence of the competition between a deformation-enhancing process and a strainrecovering process at the grain contact scale. Intergranular pressure solution can explain grain indentation of halite crystals and the overall compaction measured in the experiment. However, as the halite content increases, more and more halite-halite grain contacts can heal. In such healed or partially healed contacts, pressure solution becomes less efficient. We propose that this compaction-inhibiting mechanism provides an explanation for the reduction in compaction rate for halite concentrations greater than $70 \%$.

\subsection{Numerical simulation}

We propose that the bell-shape of the experimental compaction curves (Fig. 3) can be explained by estimating a single parameter: the ratio between the deformation rates at the halite-halite and halite-calcite contacts. To simulate the compaction, a discrete model was used (Fig. 8). For an initially fixed proportion of halite and calcite grains, a vertical column of grains was built containing roughly the same number of grains as along a vertical line in the experiments (around 200 grains). The grains were randomly located in the column. Pressure solution creep was considered to occur at the grain contacts and two contact velocities and an unknown velocity $v_{c}$ were fixed: 
1. halite-calcite contacts: normalized deformation rate $=1$. This is chosen to be a reference rate.

2. calcite-calcite contacts: deformation rate $=0$. This rate is very slow at the time scale of the experiment; however it would not be equal to zero over geological time scales.

3. halite-halite contacts: unknown deformation rate $=v_{c}$

In the column with an initially fixed proportion of halite and calcite, the number of contacts of the different kind was counted and it was therefore possible to calculate the vertical deformation over the whole column. As the grains were randomly placed in the column, the deformation rate varied slightly between the different simulations and it was thus possible to calculate the error on the deformation rate (similar to the experimental variations due to the initial arrangement of the grains).

A least squared method allowed estimating the unknown parameter $v_{c}$ by minimizing the difference between the numerical results and the experimental data. For this purpose, the experimental curve representing the vertical compaction versus the mineral composition of the column for the 100-7000 minutes interval was used (Fig. 3a). This curve was normalized so that the maximum deformation was equal to 1 . As a result of our simulations, for every $v_{c}$ value between 0 and 1 , a vertical compaction rate of the column as a function of its mineral composition was obtained (like the curve in Fig. 3b). In this model, the non linear shape of the strain vs time curve (Fig. 2) was assumed to be the same for all halite contents, the only difference being the kinetic parameter $v_{c}$. This is discussed below. The resulting simulations represented the compaction of the column versus the mineral composition for a certain unknown compaction time. For different periods of time the form of each of these curves would be the same for every constant value of $v_{c}$. Consequently, these curves could be 
normalized to the maximum deformation. Then each of these curves were superimposed on the normalized experimental curve. A value $v_{c}=0.49 \pm 0.01$ corresponded to the best squareleast fit of the experimental data (Fig. 9).

For a fixed proportion of calcite and halite grains, up to five experiments were performed (see Table 1), and this allowed an experimental error to be calculated (dotted curve on Fig. 9). Similarly, up to five numerical simulations for the same proportion of calcite and halite grains were used to estimate the numerical error due to the initial (random) arrangement of the grains. The experimental and numerical errors were less than $10 \%$ of the total deformation, as shown on Fig. 9.

\subsection{Effect of the nonlinearity of the compaction curves}

It can be seen on the experimental data (Fig. 2), that the compaction rate of mineral aggregates deforming by pressure solution creep continuously decreases with time and is not linear in time. Let us consider that the deformation rate of each type of intergranular contacts can be defined by a nonlinear function as follows:

1. halite-calcite contacts: normalized deformation rate $=1 * f_{h c}(t)$

2. calcite-calcite contacts: deformation rate $=0$

3. halite-halite contacts: unknown deformation rate $=v_{c} * f_{h h}(t)$

The only difference between these definitions and those presented previously is the presence of the functions $f_{h c}(t)$ and $f_{h h}(t)$, which represent the time-dependence of the compaction rate. The question is to know if the nonlinear shape of this function is the same for all halite contents between $40 \%$ and $100 \%$. For this, we compare the experimental data of Fig. 3a at different time intervals. This is seen on the experimental curve of Fig. 6 where are presented the experimental data for three different deformation intervals: [100-300], [300-3000] and [3000-7000] minutes. The shape of the curves are similar within the limits of $40 \%-100 \%$ of 
halite content (there is an additional factor that plays a significant role for the mixtures with halite content from $0 \%$ to about $40 \%$, see section 3.2). This indicates that the bell-shaped form of the curve in Fig. 3a is time-independent. For a fixed mineral percentage, the ratio between the rates of deformation of two types of contacts is therefore constant during the experiment; consequently $f_{h c}(t)=f_{h h}(t)$.

The purpose of the model is to obtain a bell-shaped curve (compaction rate normalized to the maximum compaction rate versus proportion of halite grains) and to compare it with the experimental one (Fig. 9). As $f_{h c}(t)=f_{h h}(t)$, the ratio between the rates of deformation of two types of contacts remains constant during the experiment. This indicates that for every fixed duration of experiment the ratio between the values of deformation obtained for different columns only depends on the mineral percentage in these columns. Hence, the form of the simulation curve on Fig. 9 obtained does not depend on the elapsed time for a constant $v_{c}$.

\subsection{Analytical solution}

Another way of estimating the effect of halite proportion on compaction rate is to solve the problem analytically by defining a probability for each type of grain-grain contact. If $P_{h}$ is the proportion of halite grains and $P_{c}=1-P_{h}$ the proportion of calcite grains, then the following expression can be defined, $P_{h h}=P_{h} * P_{h}$, which is the probability of a halite-halite contact in the column of aggregate. Similarly, $P_{c c}=P_{c}^{2}=\left(1-P_{h}\right)^{2}$ is the probability of a calcite-calcite contact and $P_{h c}=2 P_{h} P_{c}=2 P_{h}\left(1-P_{h}\right)$ is the probability of a halite-calcite contact. With these definitions, it is easy to check that $P_{h h}+P_{h c}+P_{c c}=1$. The deformation rate of the aggregate is the sum of the deformations at each contact $\dot{\varepsilon}=v_{c} * P_{h h}+1 * P_{h c}+0 * P_{c c}$, where $v_{c}$ is the deformation rate at a halite-halite contact. The parameters 1 and 0 stand respectively for the deformation rates at a halite-calcite contact (rate normalized to 1) and at a 
calcite-calcite contact (rate equal to zero on the time scale of the experiment). Using the previous definitions of the probabilities, the following expression is obtained $\dot{\varepsilon}=\left(v_{c}-2\right) P_{h}^{2}$

$+2 P_{h}$. This deformation rate is at a maximum when $\frac{\delta \dot{\varepsilon}}{\delta P_{h}}=0$. This happens when $P_{h}=1 /(2-$ $\left.v_{c}\right)$. For the experiments, a value $v_{c}=0.49$ was found and this gives the maximum deformation for a proportion of halite $P_{h}=66 \%$. This analytical result is in agreement with experimental data: the maximum compaction actually occurs for a proportion of halite grains around this value. From this analytical analysis, a relationship has been obtained between the deformation rate at halite-calcite contacts and the proportion of halite for which the rate of compaction of the aggregate is maximum.

\subsection{Effect of calcite grain acute angles}

The geometry and the hardness of the solids at the contacts may have an influence on the rate of polymineralic aggregates deformation. On one hand, the contact areas between two halite grains increased with time as compaction progressed. This fact implies that the normal stress decreased with time on such grain contacts. On the other hand, for halite-calcite contacts, the calcite grains did not dissolve and acted as hard indenter with acute angles. In this case, the reduction in normal stress at the contact would not be as large as for halite-halite contacts. Hence, the rate of compaction should not decrease.

To discuss this interpretation, it will be recalled that it has been demonstrated that $f_{h c}(t)=$ $f_{h h}(t)$, i.e. the function that describes the slowing down of compaction rate with time, is the same for halite-halite and halite-calcite contacts (see section 4.3). On the other hand, the assumption of a significant influence of calcite acute angles on the rate of deformation implies an important difference in the geometrical evolution with time of the two types of 
contacts. As a consequence, $f(t)$ should be different for these two different contacts. That is not the case. Consequently, possible difference in geometry between halite-halite and halitecalcite contacts should not have a significant influence on the rate of contact deformation in the experiments.

\section{Conclusions}

This article reports on the result of a series of compaction experiments on aggregates containing calcite and halite mixed together in various proportions. In the sample, halite acts as a soft material that deforms easily, whereas calcite grains correspond to hard objects that do not deform during the time scale of the experiment. It is shown that the rate of deformation depends to a considerable extent on the relative proportion of these minerals and that increasing the proportion of "hard" particles decreases the strength of the aggregate. In particular, the fastest compaction rate does not occur with a sample containing $100 \%$ halite. The compaction rate is found to be up to $24 \%$ faster for a proportion of halite grains between $45 \%$ and $75 \%$ than for a pure halite system. This indicates competition between two mechanisms at granular scale: on one hand, stress enhanced dissolution at grain contact ; on the other hand, some halite-halite contacts tend to heal and to inhibit further pressure solution creep. The calcite grains enhance pressure solution creep because they prevent contact healing between halite grains. This effect can be included in a simple model and quantified by a single parameter $v_{c}$, extracted from the experiments, which describes the effectiveness of pressure solution at the various grain contacts.

Natural rocks are rarely monomineralic and contain various proportions of minerals. The experimental results described here indicate that the deformation rate of rocks in the presence of reactive fluids depends to a large extent on the relative amount of each mineral. When controlled by pressure solution, compaction of monomineralic rocks can be slower than that 
of polymineralic rocks as healing of grain-grain contacts can occur. This result has major applications for the rheology of rocks in the earth's upper crust where mineralogical composition changes with progressive deformation. For example, it is known that pressure solution can play an important role in gouge deformation (Kanagawa et al. 2000). The present study indicates that a polymineralic gouge can deform more easily than a monomineralic one, with the same grain size structure. Moreover, starting from rocks with both soluble and insoluble minerals, the areas initially formed by deposition only (with $100 \%$ of soluble mineral) seem to deform not so easily as the areas with mixed composition. This is commonly observed in natural deformation.

Acknowledgments: The project has been supported by the CNRS (Action Thématique Innovante) and $A N D R A$. We would like to thank D. Tisserand, C. Pequegnat and L. Jenatton for their technical help.

\section{References}

den Brok, S.W.J., 1998. Effect of microcracking on pressure solution strain rate: The Gratz grain-boundary model. Geology 26, 915-918.

Hickman, S.H., Evans, E., 1991. Experimental pressure solution in halite -The effect of grain interphase boundary structure. Journal of the Geological Society, London 148, 549-560.

Hickman, S.H., Evans, E., 1995. Kinetics of pressure solution at halite-silica interfaces and intergranular clay films. Journal of Geophysical Research 100, 13113-13132.

Janssen, H. A., 1895. Versuche uber getreidedruck in silozelen. Zeitschrift Vereins Deutsche Ing. 39, 1045-1049.

Kanagawa, K., Cox, S., Zhang, S., 2000. Effect of dissolution-precipitation processes on the strength and mechanical behavior of quartz gouge at high-temperature hydrothermal conditions. Journal of Geophysical Research 105, 11115-11126. 
Paterson, M.S., 1973. Nonhydrostatic thermodynamics and its geologic applications. Reviews of Geophysics and Space Physics 11, 355-389.

Renard, F., Dysthe, D.K., Feder, J., Bjørlykke, K., Jamtveit, B., 2001. Enhanced pressure solution creep rates induced by clay particles: Experimental evidence from salt aggregate. Geophysical Research Letters 28, 1295-1298.

Rutter, E.H., 1976. The kinetics of rock deformation by pressure solution. Philosophical Transactions of the Royal Society of London 283, 203-219.

Rutter, E.H., Wanten, P.H., 2000. Experimental study of the compaction of phyllosilicatebearing sand at elevated temperature and with controlled porewater pressure. Journal of Sedimentary Research 70, 107-116.

Schutjens, P.M.T., Spiers, C.J., 1998. Intergranular pressure solution in NaCl: Grain-to-grain contact experiments under optical microscope. Oil and Gas Technology 54, 729-750.

Wheeler, J., 1992. Importance of pressure solution and coble creep in the deformation of polymineralic rocks. Journal of Geophysical Research 97, 4579-4586.

Weyl, P.K., 1959. Pressure solution and the force of crystallization - a phenomenological theory. Journal of Geophysical Research 69, 2001-2025. 
Table 1. Experimental conditions for the fourty-nine experiments of compaction of halitecalcite aggregates. Experiments labeled with an asterisk correspond to measurements performed to check the reproducibility.

\begin{tabular}{lll}
\hline wt\% of halite & \%o of halite grains & number of experiments \\
\hline $0 \%$ & $0 \%$ & 1 \\
$2.3 \%$ & $2.0 \%$ & 1 \\
$4.8 \%$ & $4.1 \%$ & 2 \\
$10 \%$ & $8.6 \%$ & 2 \\
$20 \%$ & $17.6 \%$ & 3 \\
$30 \%$ & $26.7 \%$ & 3 \\
$40 \%$ & $36.2 \%$ & 3 \\
$50 \%$ & $46.0 \%$ & 4 \\
$60 \%$ & $56.1 \%$ & 5 \\
$70 \%$ & $66.5 \%$ & $5+2 *$ \\
$80 \%$ & $77.3 \%$ & 3 \\
$87.5 \%$ & $85.6 \%$ & 3 \\
$94 \%$ & $93.0 \%$ & 2 \\
$100 \%$ & $100 \%$ & $3+5 *+1$ dry +1 paraffine \\
\hline
\end{tabular}




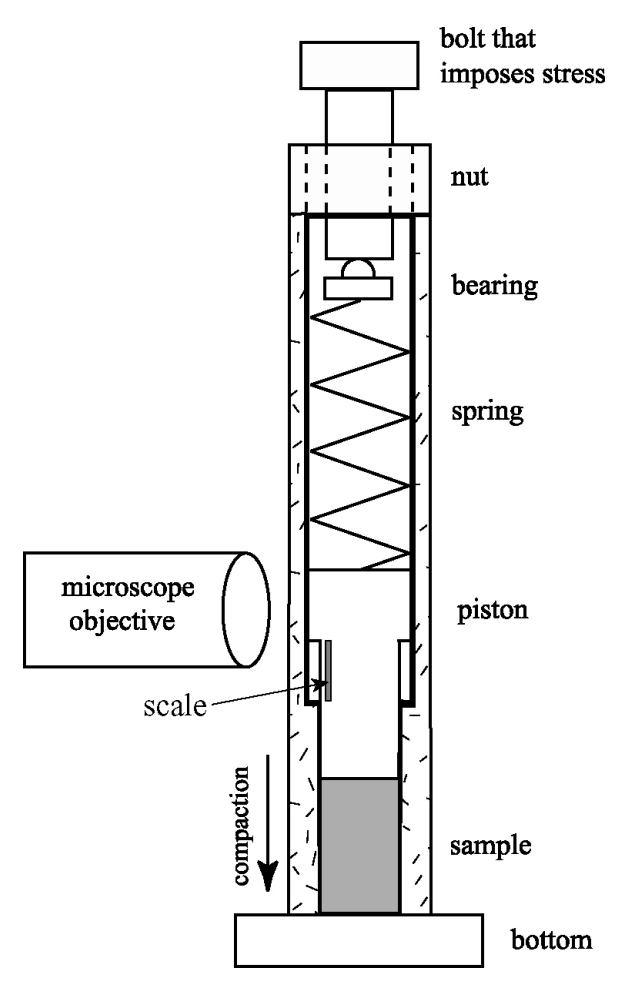

Fig. 1. Schematic drawing of the experimental set-up. The samples of halite and calcite powder were compacted in a transparent Plexiglas cell (internal diameter $6 \mathrm{~mm}$ ). The vertical stress was imposed by a screw and transmitted through a spring. The reading was taken through the microscope by following the vertical displacement of the piston on which a micrometer scale was glued. The measurements were performed for five days. Six of such cells were built and mounted in front of six microscopes. All the microscopes and cells stood in a thermostatically-controlled Plexiglas box. 


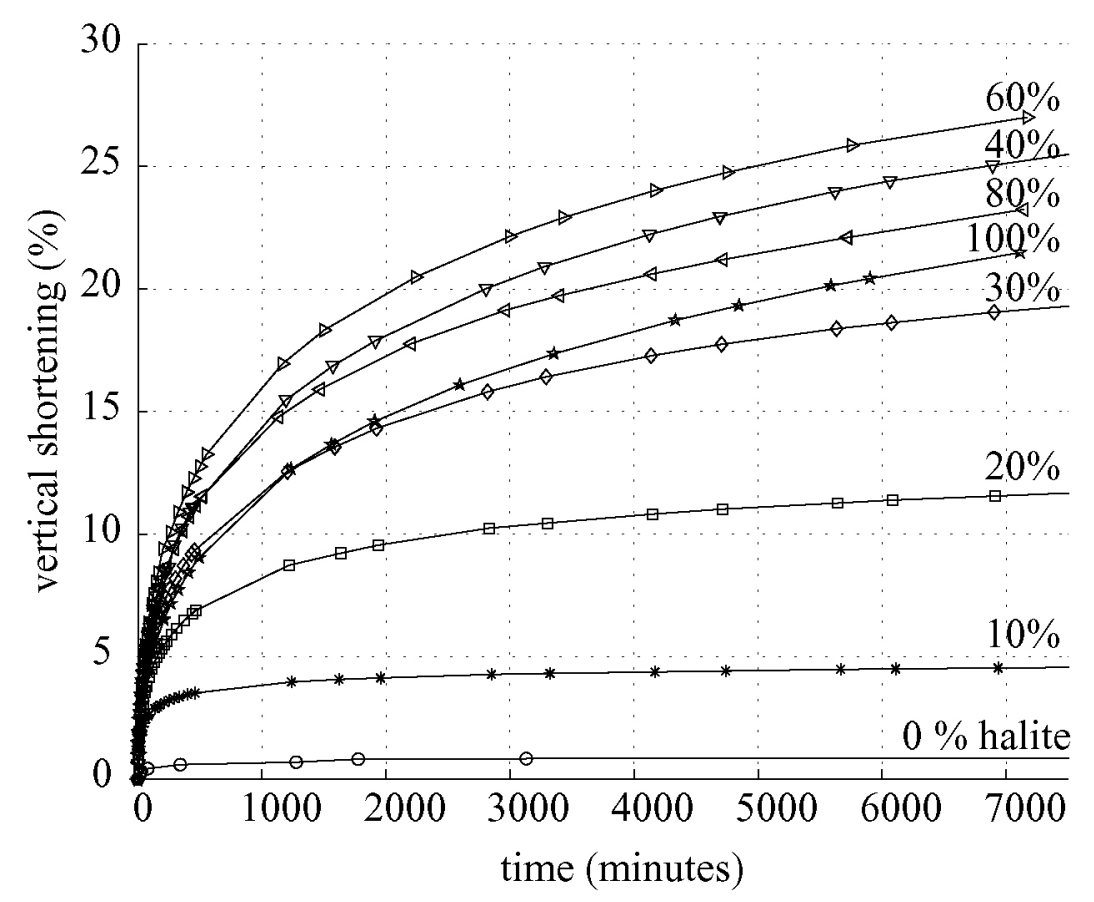

Fig. 2. Result of drained compaction experiments. Compaction curves $\varepsilon(\mathrm{t})=\left(\mathrm{x}_{0}-\mathrm{x}(\mathrm{t})\right) / \mathrm{x}_{0}$ for different samples show that the total amount of compaction after 7000 minutes (roughly 5 days) depends on the relative proportion of halite and calcite grains. The highest finite compaction does not occur for a proportion of $100 \%$ halite grains. 

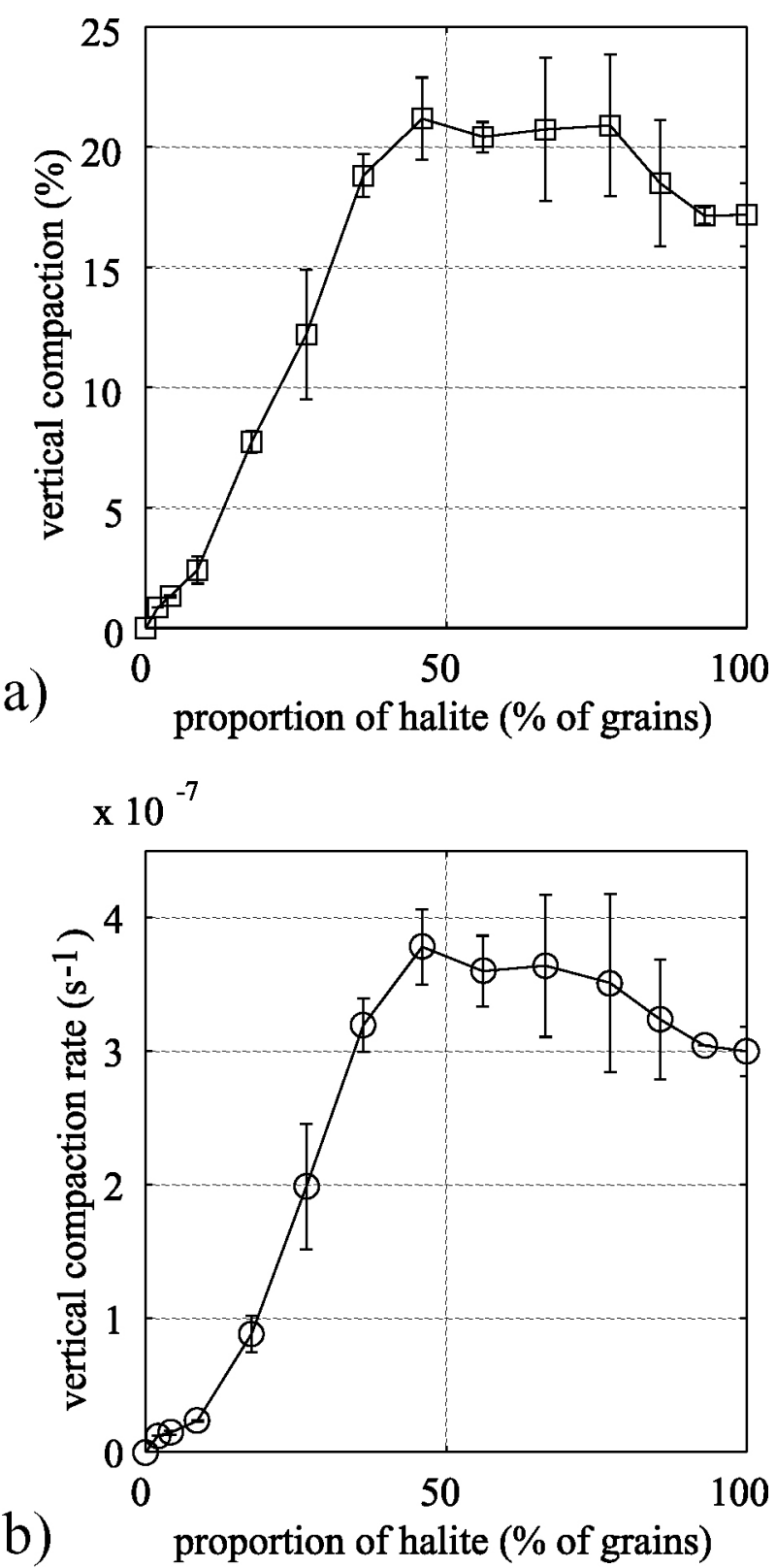

Fig. 3. Compaction (\%) during the 100-7000 minutes deformation period and compaction rate $\left(\mathrm{s}^{-1}\right)$ after 7000 minutes of compaction. a) Effect of the mineralogical composition on the amount of vertical shortening of the aggregate in the interval 100-7000 minutes. The smallest amount of compaction is obtained for pure calcite. When halite is introduced in the aggregate, the amount of compaction increases as well, up to the content of halite grains of about $45 \%$. Then compaction remains practically unchanged in the range $45 \%-75 \%$. For higher halite contents, the amount of compaction decreases. b) Compaction rates at 7000 minutes. Here again, there is a range of halite grains contents for which the deformation rate is the greatest. 


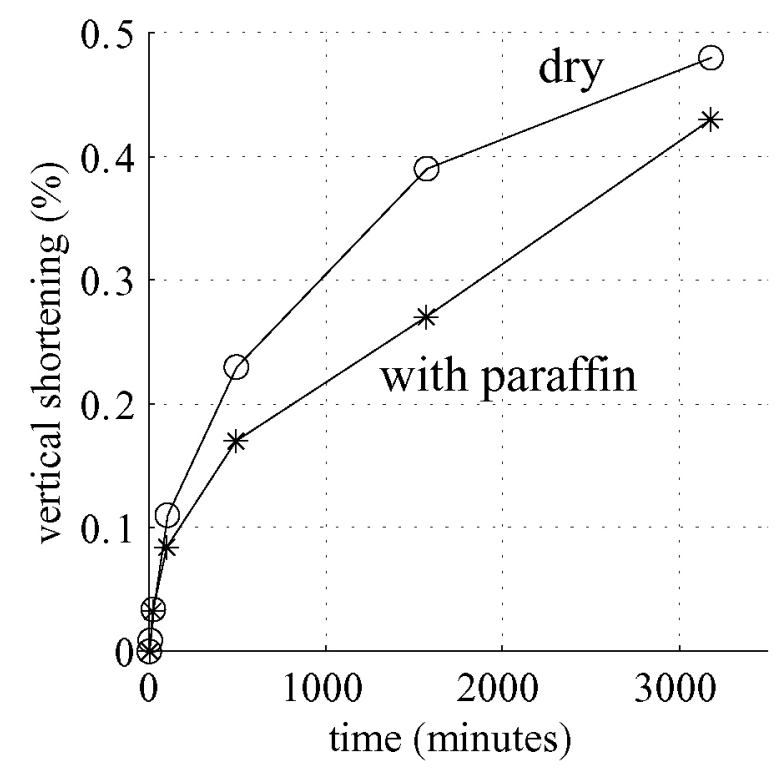

Fig. 5. Compaction curves for dry halite aggregate (circles) and halite aggregate filled with liquid paraffin (asterisk). For these conditions, the compaction remains very low (less than $0.5 \%$ ) even after several days, to be compared with more than $15 \%$ with wet $100 \%$ halite aggregates. 


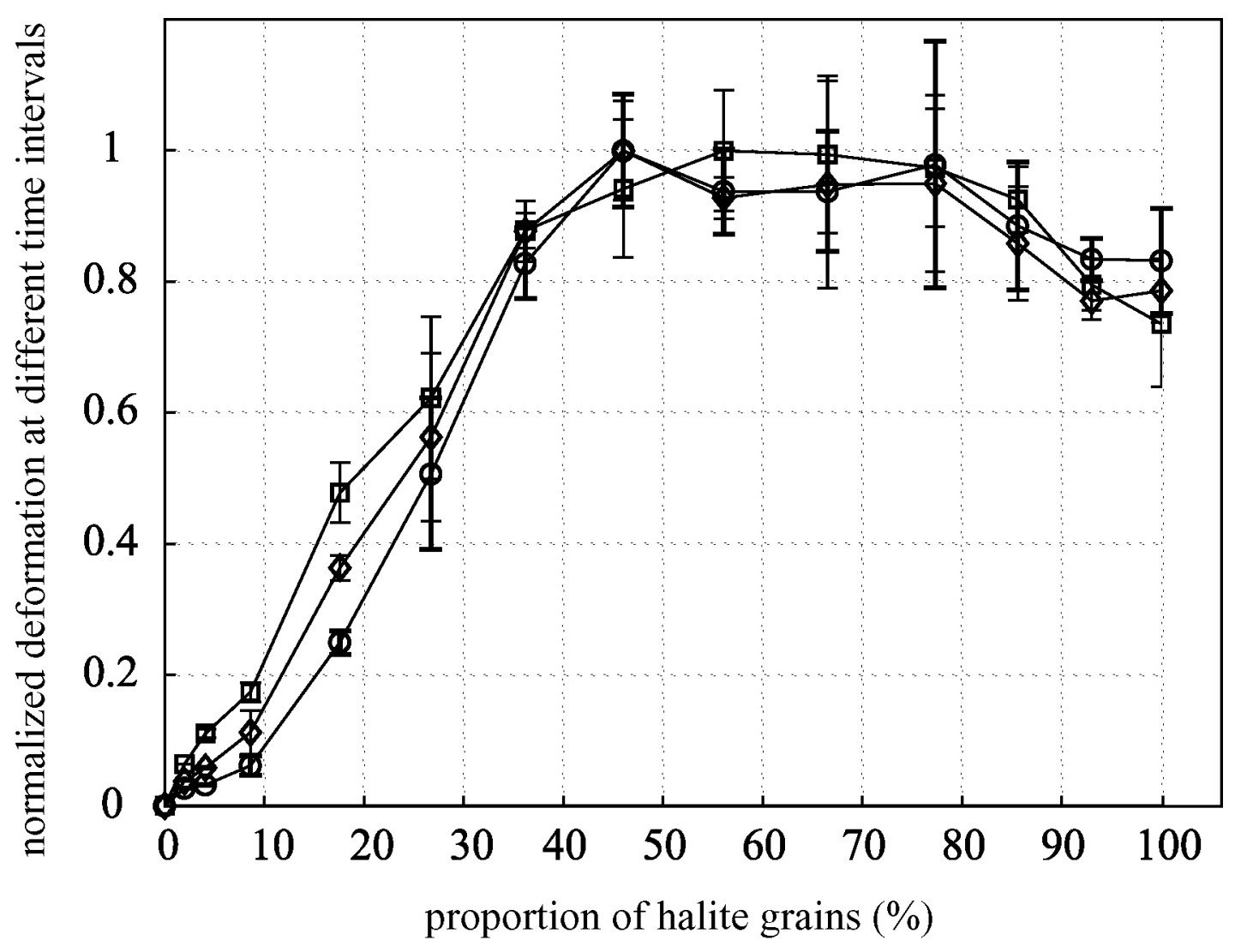

Fig. 6. Effect of the mineralogical composition on the amount of vertical shortening on the aggregate in the range 100-300 (squares), 300-3000 (diamonds), and 3000-7000 (circles) minutes. The three curves are normalized to the average maximum deformation of the tested samples at the given elapsed time and they show the same trend, within experimental errors. The mixtures with halite contents between 0 to about $40 \%$ do not exhibit this behavior. The rate of deformation goes down during progressive deformation for halite proportions ranging between $10 \%$ and $40 \%$ (squares, through diamonds, to circles). 

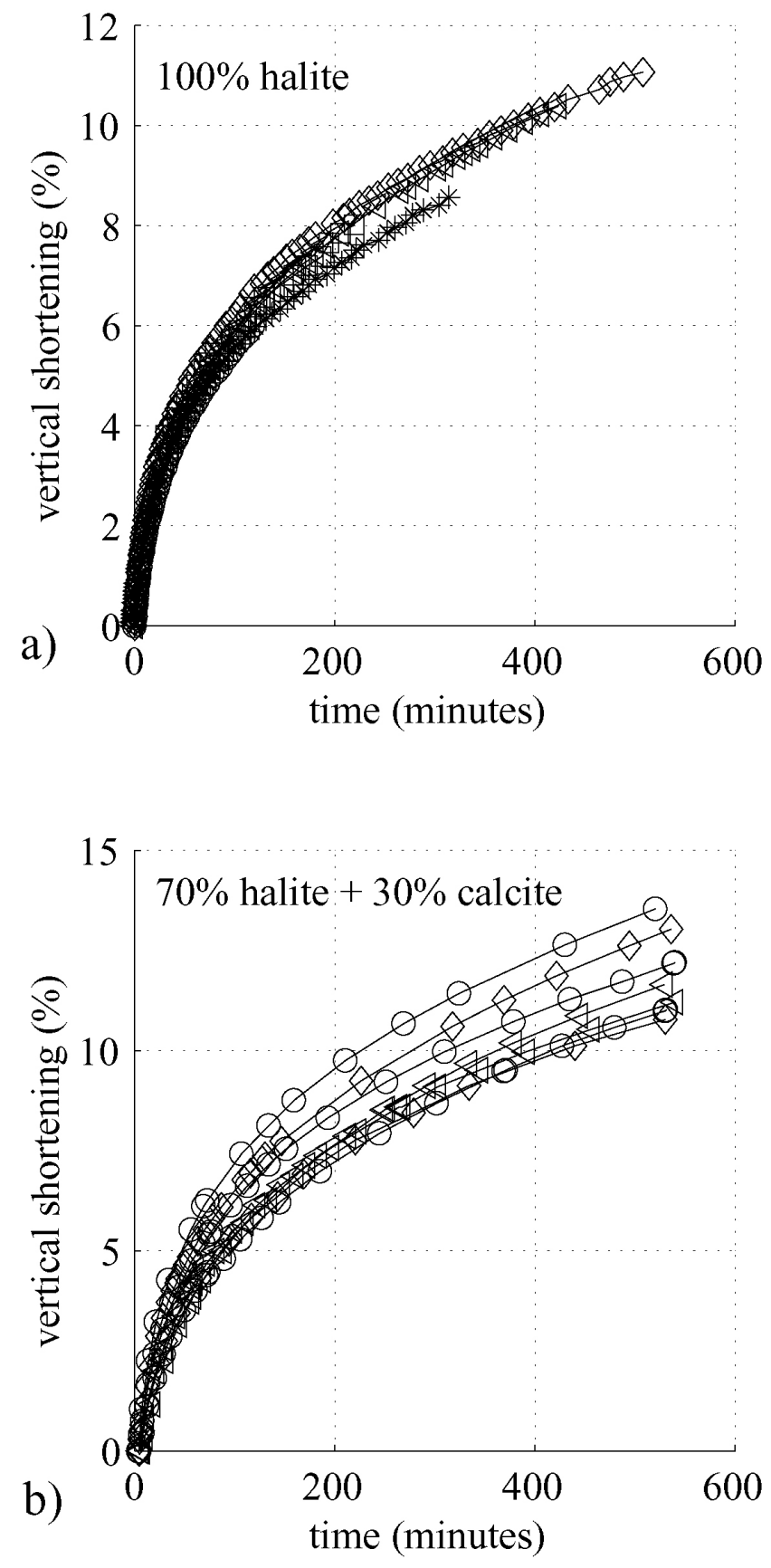

Fig. 4. a) Reproducibility for five experiments with pure halite aggregates under the same experimental conditions. The initial heights of each sample are $27 \mathrm{~mm}$ (circles), $26 \mathrm{~mm}$ (asterisk), $25.5 \mathrm{~mm}$ (diamonds), $14 \mathrm{~mm}$ (squares), $13 \mathrm{~mm}$ (triangles). The powders spent one day (squares and triangles) and four days (circles, asterisks and diamonds) in a saturated solution of halite before starting experiment. b) Reproducibility of seven experiments with $70 \%$ of halite content aggregates under the same experimental conditions. The initial heights of the samples are $19 \mathrm{~mm}$ (triangles), $12 \mathrm{~mm}$ (circles), $10.5 \mathrm{~mm}$ (diamonds). 
a
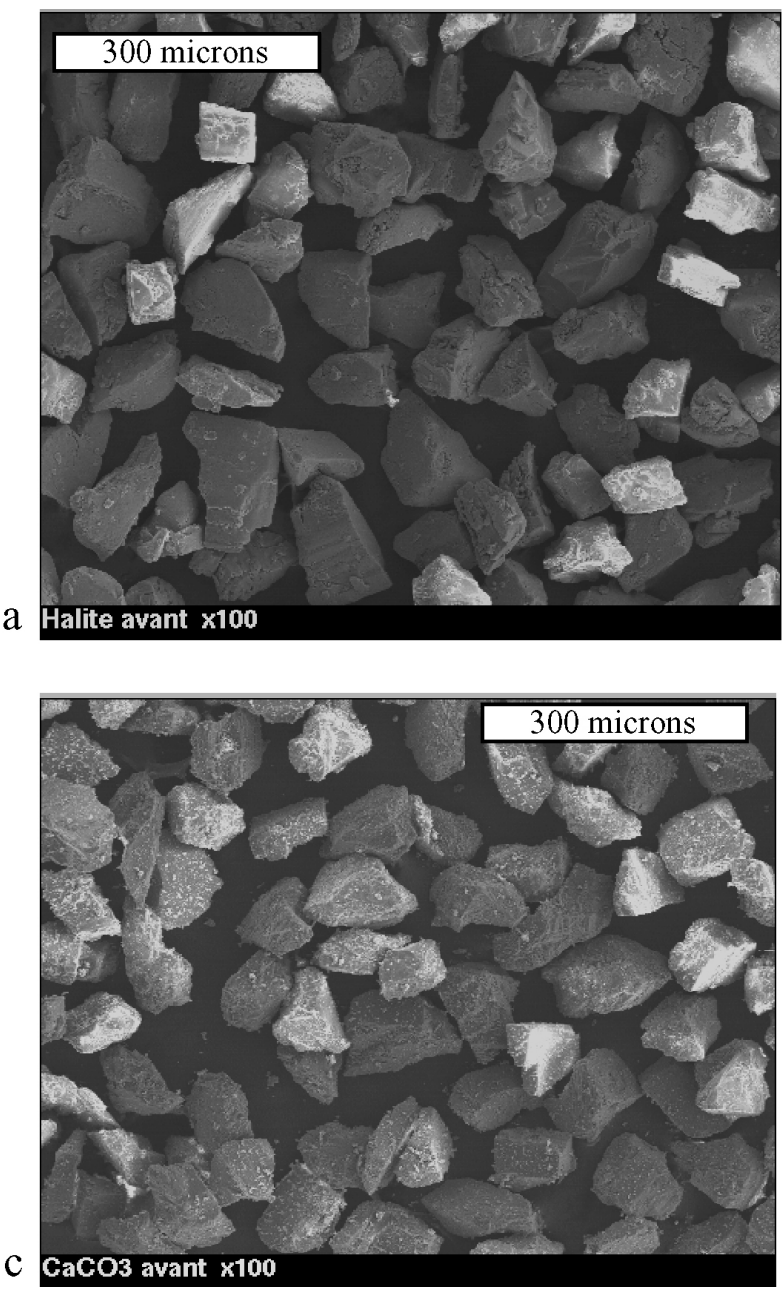
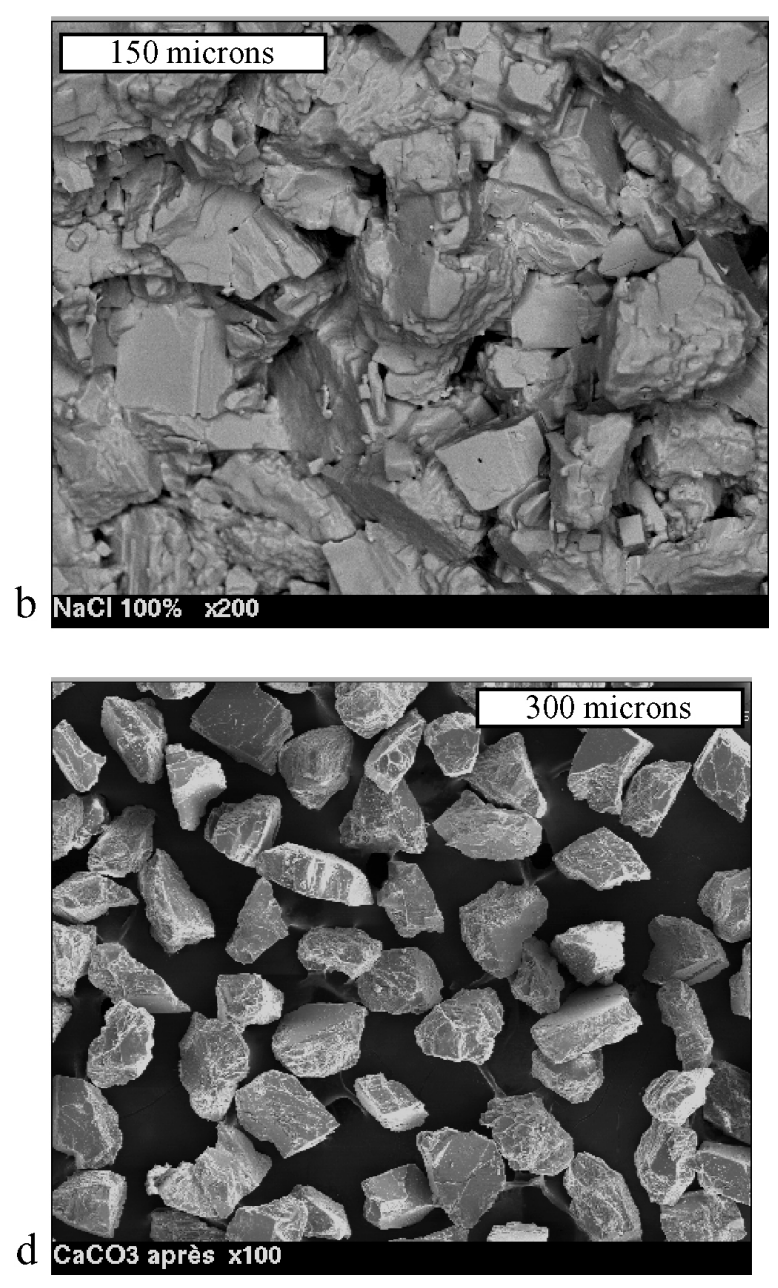

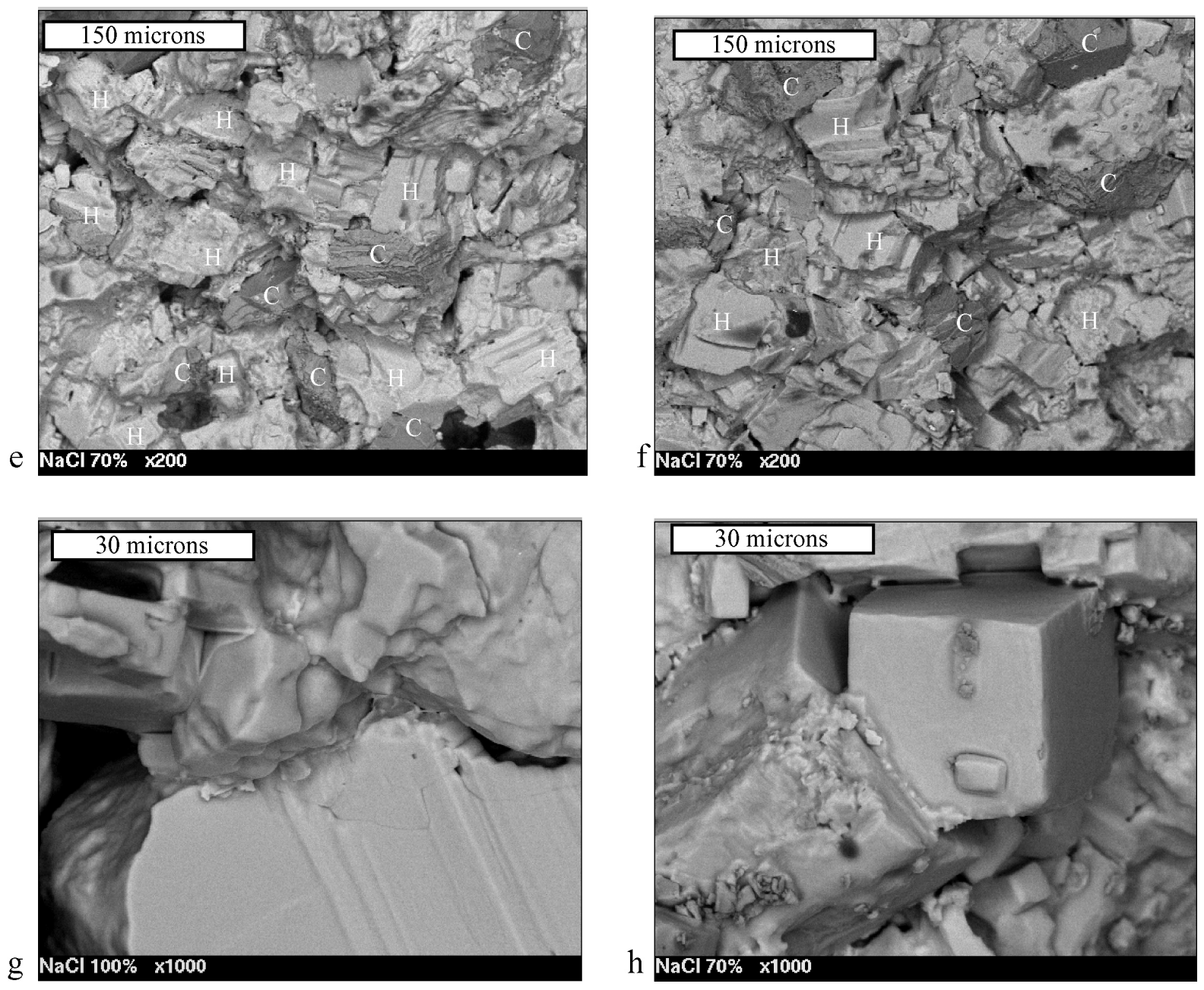

Fig. 7. Scanning electron microscope (SEM) pictures of the samples before and after deformation. a) Initial halite powder. b) $100 \%$ halite powder after compaction. c) Initial calcite powder. d) $100 \%$ calcite powder after the experiment. As calcite grains did not deform significantly, they look like very similar to the initial powder. e-f) $70 \%$ halite $+30 \%$ calcite aggregate after compaction ; the halite grains $(\mathrm{H})$ appear in lighter gray than the calcite grains (C). g-h) Examples of pressure solution patterns at grain contacts in $100 \% \mathrm{wt}(\mathrm{g})$ and $70 \% \mathrm{wt}$ (h) halite samples. 


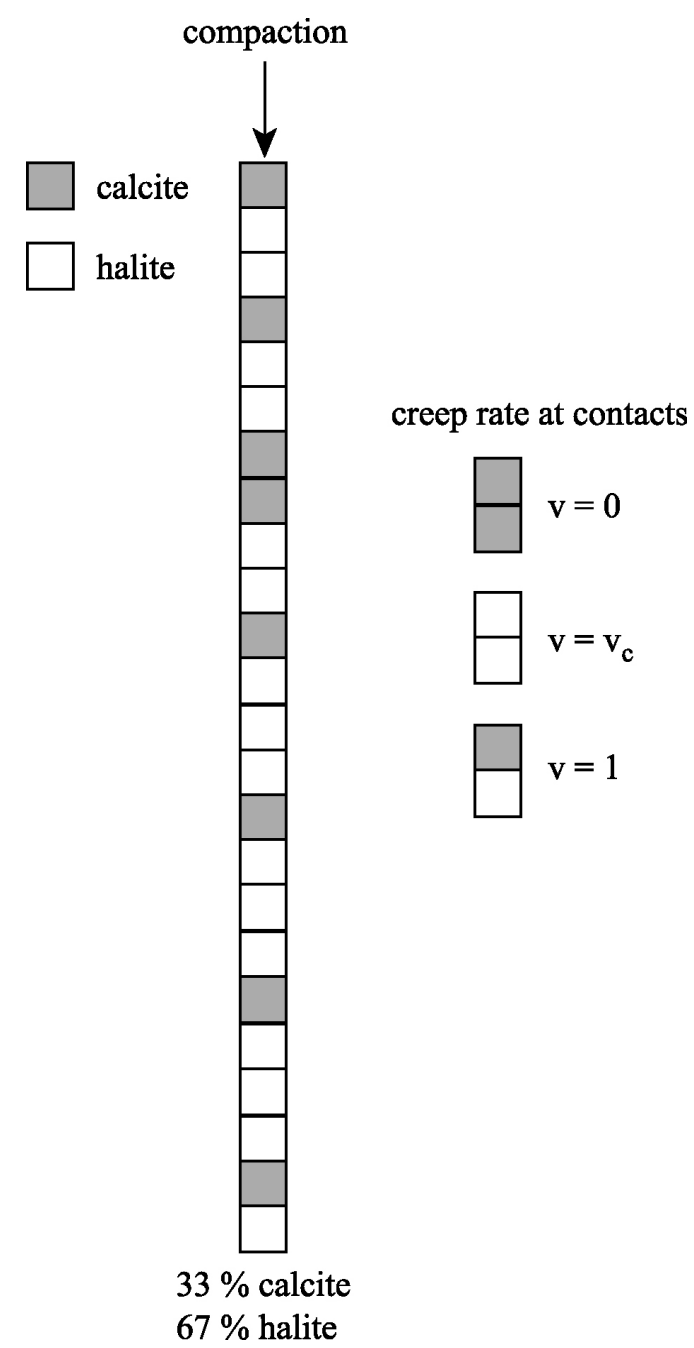

Fig. 8. Simulation of the compaction experiment by discrete elements: grains are added on a vertical column so that the total number of grains is comparable to that in the experiments (around 200). The position of each grain (halite or calcite) is chosen randomly such that the relative proportion of each mineral is fixed (here $33 \%$ calcite). The result is a vertical pile of grains with an initially fixed proportion of halite and calcite. The deformation rate is defined for each grain contact: halite-calcite contacts deform with a velocity 1 , calcite-calcite contacts do not deform and halite-halite contacts deform with a velocity $v_{c}$, which is the only unknown parameter of the simulation. Minimization between the experimental data and the simulated results for different values of $v_{c}$ between 0 and 1 enables the best value for $v_{c}$ to be calculated. 


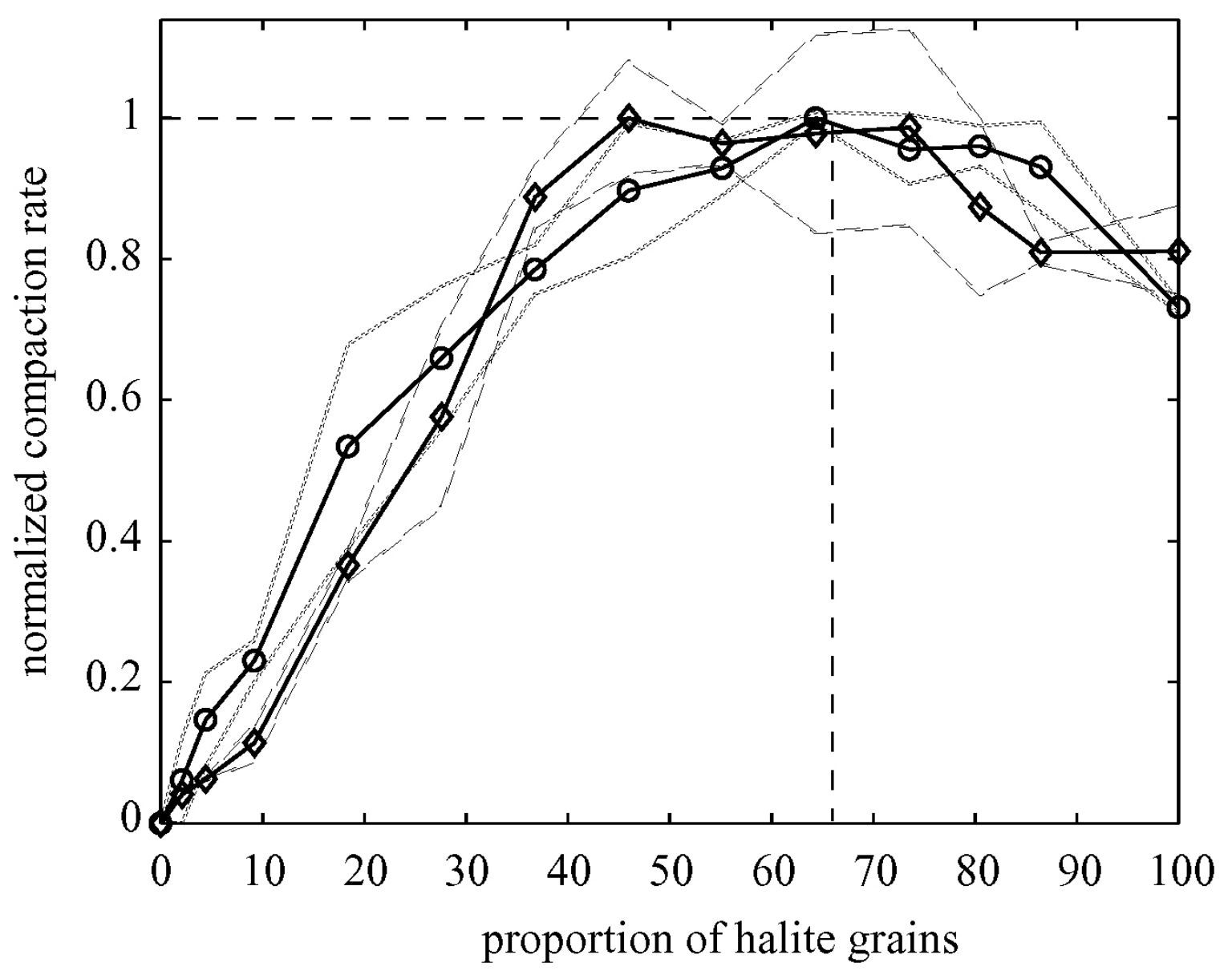

Fig. 9. Experimental data (diamonds) for the interval 100-7000 minutes and numerical results (circles) showing that $v_{c}=0.49 \pm 0.01$ represents the best fit of the experimental data. For each calcite-halite proportion, three to five experiments were performed and three to five numerical simulations were made with a different initial random arrangement for the calcite and halite grains. Both experimental (dashed curve) and numerical (dotted curve) errors are comparable. The horizontal and vertical dashed lines give the position of the maximum deformation rate. 